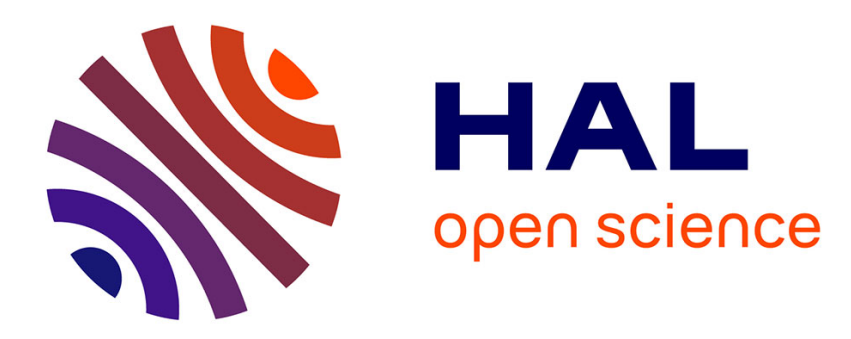

\title{
Impact of renewable energy micro-power plants on power grids over Africa
}

\author{
H. Terfa, Lotfi Baghli, R. Bhandari
}

\section{To cite this version:}

H. Terfa, Lotfi Baghli, R. Bhandari. Impact of renewable energy micro-power plants on power grids over Africa. Energy, 2021, pp.121702. 10.1016/j.energy.2021.121702 . hal-03318776

\section{HAL Id: hal-03318776 \\ https://hal.univ-lorraine.fr/hal-03318776}

Submitted on 17 Aug 2021

HAL is a multi-disciplinary open access archive for the deposit and dissemination of scientific research documents, whether they are published or not. The documents may come from teaching and research institutions in France or abroad, or from public or private research centers.
L'archive ouverte pluridisciplinaire HAL, est destinée au dépôt et à la diffusion de documents scientifiques de niveau recherche, publiés ou non, émanant des établissements d'enseignement et de recherche français ou étrangers, des laboratoires publics ou privés. 


\title{
Impact of renewable energy micro-power plants on power grids over Africa
}

\author{
H. Terfa ${ }^{\text {a,* }}$, L. Baghli ${ }^{\text {a,b }}$, R. Bhandari ${ }^{c}$ \\ ${ }^{\text {a }}$ LAT, Laboratoire d'Automatique de Tlemcen, \\ Université de Tlemcen, 13000 Tlemcen, Algeria \\ e-mail: hani.terfa@univ-tlemcen.dz \\ ${ }^{\mathrm{b}}$ Université de Lorraine, GREEN, F-54000 Nancy, France \\ e-mail: lotfi.baghli@univ-tlemcen.dz \\ ${ }^{\mathrm{c}}$ Institute for Technology and Resources Management in the Tropics and Subtropics \\ TH Köln (University of Applied Sciences), Cologne, Germany \\ e-mail: ramchandra.bhandari@th-koeln.de
}

\begin{abstract}
Providing electricity in African countries through the extension of the grid is very expensive, due to its highly distributed population. Thereby, the use of distributed renewable energy micropower plants is the proposed solution.

In this paper, we present the research studies at our laboratory to achieve building prototypes of smart distributed renewable energy micro-power plants. Four types of micro-power plants are being developed; a $1.5 \mathrm{~kW}$ Wind Turbine Emulator based on a Double Fed Induction Generator, a $1.5 \mathrm{~kW}$ Wind Turbine Emulator based on a Synchronous Generator, a $1.5 \mathrm{~kW}$ Photovoltaic system with Grid Tie Inverters and finally, a $250 \mathrm{~W}$ Photovoltaic micro-power plant connected through a self-made single-phase Grid Tie Inverter.

In addition, we have a simulated power grid with conventional power plants, power system stabilizers and automatic voltage controllers and other modelled power plants running in real time on embedded processors (Raspberry PI3). To ensure the data flow between all these micropower plants and the simulated power grid, we use a Firebase Database; the experimental benches send data and receive orders to/from the database thanks to Wi-Fi connected microcontrollers ESP8266. Load Flow and Transient Stability studies are considered.
\end{abstract}

\section{KEYWORDS}

Micro-Power Plants, Smart grid, Distributed generation, Firebase Database, Power System Stabilizers.

\section{HIGHLIGHTS}

- Four experimental prototypes of micro-power plants are presented

- MPPT extraction algorithms are performed on the micro-power plants

- Communication technologies are the key to achieve the new approach on smart grids

- Intermittent renewable sources have negative impacts on power grid stability

- Power System Stabilizers are important to enhance the stability of power grids

\footnotetext{
* Corresponding author.

E-mail address: hani.terfa@univ-tlemcen.dz
} 


\section{INTRODUCTION}

The United Nations estimates that the current population of Africa is more than 1.32 billion with more than $56 \%$ of people living in non-urban areas [1]. Although Africa is rich by renewable and non-renewable energy sources (A Photovoltaic panel produces twice energy in Africa than it will produce in Central Europe on average), the generation of electricity is not yet satisfied [2], [3]; making a mismatch between the generation and the consumption, which lead to a low power service and many blackouts and outages [4]. This affects directly the economic growth of African countries [5], [6]. The conventional solution of extending the power grid face many constraints, among them; distributed population, difficult terrains, long distances between the utility grid and the loads and the expensive cost [7]. However, with the development of renewable energy technologies, and with the increase of fuel prices [8]-[10], the integration of distributed renewable energy Micro-Power Plants (MPP) is more favorable to enforce the weakness of the power grids in Africa.

Many countries on Africa continent are enabling high investments in solar and wind energies. Figure 1 shows the Law-Carbon scenario based on African Development Bank (AfDB) a New Deal on Energy for Africa policy document, Balmorel model [11]. This model shows the power sector expansion of the 54 African countries by 2030. It is a dynamic approach for the integration of renewable energies. It includes real data for wind and irradiance to match the supply with the demand through the day. It is shown that the installed capacity from renewable energies in Africa will exceed $50 \%$ of the total production by 2030 . For example, Algeria, the biggest country in Africa, has launched an ambitious program (the Algerian Renewable Energy Development and Energy Efficiency Program-PENREE) which consist of installing up to $22000 \mathrm{MW}$ of power generating capacity from renewable energy sources by 2030 [12]. These important capacities open the doors to study the impact of installing many renewable energy MPP and Power plants, and to analyse their mutual interaction not only in islanded mode, but also in grid-connected mode.

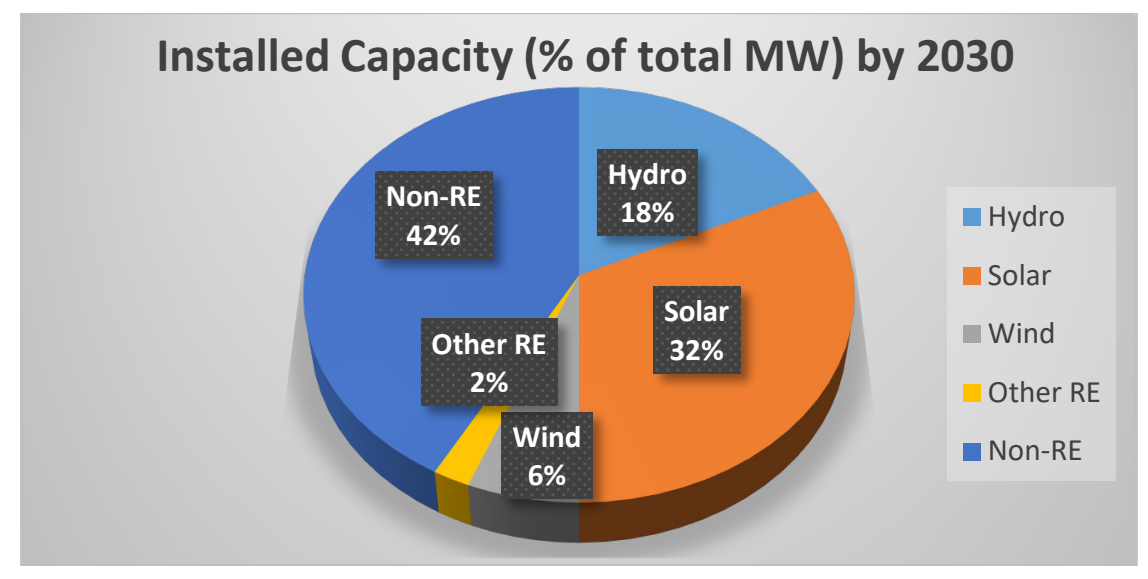

Figure 1. The renewable energy transition in Africa, a view towards 2030

The concept of integration of distributed renewable energy MPP for the development of microgrid will be most significant in the near future [13]. This new approach consists in putting many renewable energy MPP near the customers and some of them will be part of the home itself. The idea is to turn the consumer into a prosumer that can produce energy and consume it at the same time. These MPP are connected, through inverters [14] to the distribution network, which is connected to the high voltage power grid [9]. This approach is different from the conventional one where the power plants are located far from the loads and where there are many power 
losses in the transmission line (Copper losses, Magnetic Losses, Corona effect, and skin effect) [15]. In addition, $30 \%$ of the cost for delivering electricity is due to the transmission system [16]. Distributed renewable energy MPP are usually installed in combination with energy storage technologies (ESTs) such as Li-ion batteries, lead-acid, pumped hydro storage and supercapacitor energy storage [17]. In general, the ESTs' principle is to charge a storage facility in the time of excess electricity production and discharge it when needed [18]. This process is characterized by the round-trip efficiency which is the ratio of electricity stored into the facility that is subsequently recovered [19].

Distributed renewable energy MPP give a clean energy and help to reduce the Green Houses Emissions (GHE) [20]. Nevertheless, as we cannot store as much energy as we want in the batteries, the integration of distributed renewable energy MPP brings new challenges for the stability of the power grid and for the quality of service [21]. It is known that renewable energies have an intermittent generation that directly varies with weather conditions (Clouds, Sun, Wind, etc.), the energy output can go from zero on a cloudy day to the maximum value spontaneously and vice versa (Figure 2). Certainly, when its power capacity exceeds certain percentage, the disturbances will be more important [22], [23]. To minimize the fast changes in the generated power and improve reliability and service, we need a new approach of power network control, making full use of communication technology. This will result in Smart Distributed Renewable Energy Micro-Power Plants.

The Figure 2 shows the intermittent aspect of generated power from two Photovoltaic (PV) panels $(500 \mathrm{~W})$ in summer on a cloudy afternoon at Tlemcen, Algeria.

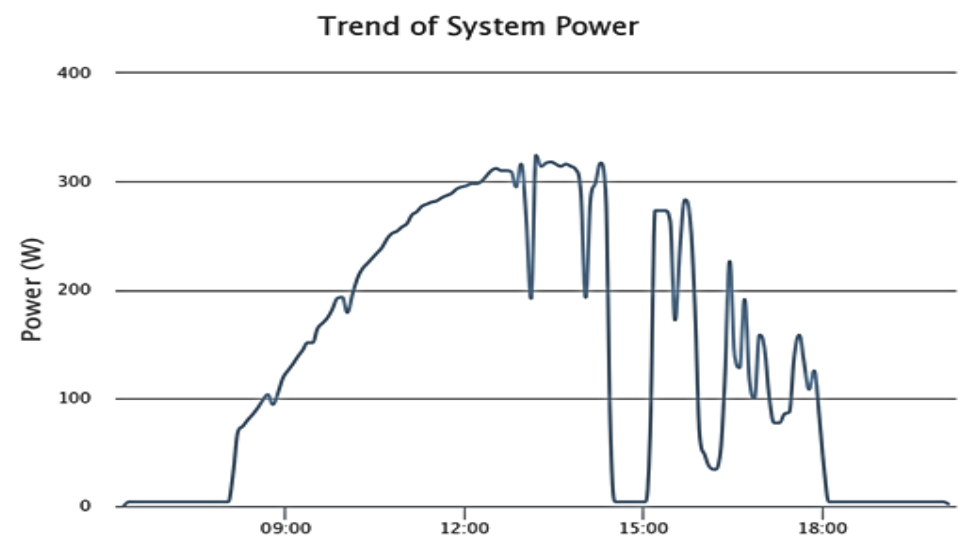

Figure 2. Experimental curve of PV power in the summer at Tlemcen, cloudy afternoon

The work presented in this paper is a part of a big project consisting in managing electricity produced from different types of renewable energy MPP to match the supply with the demand instantaneously and conserve the stability of the power grid. To achieve this goal, the project is divided into many parts: 1- Mastering the active and reactive power produced from all the MPP (both experimental and simulated ones). 2- Mastering the data flow between all the MPP, the emulated power grid, the external supervisor (android application or PC) and the firebase database. 3- Studying the impacts of integrating renewable energy MPP on power grids in term of frequency and voltage stability. 4- Develop strategies (centralized or decentralized control) to drive the swarm of MPP in a way that each one produces an amount of power proportional to its installed capacity and to other producers to respect the load/production equilibrium, to 
conserve the stability of the power grid, and to enhance the quality of service. In this paper, we present the overall MPP involved in our project in section II. In addition, we present the issues we faced when performing communication protocols between all the parts of the system (MPPs, emulated power grid, external supervisors, DB). In section III, we present the results and we discuss them. We emphasize in this section the impact of renewable energy MPP integration in power grids in term of frequency and voltage stability. Developed programs that compute the load flow, the transient stability, the power system stabilizers and the power injection from renewable energy MPP at the grid buses are also considered. Finally, we present the conclusion and the perspectives in section IV.

\section{MATERIALS AND METHODS}

\subsection{Experimental micro-power plants}

Experimental prototypes of smart MPP are developed at the Laboratoire d'Automatique de Tlemcen (LAT), Algeria.

\subsubsection{Wind turbine emulator based on a Double Fed Induction Generator}

Figure 3 shows the overall structure of the emulator of the wind energy conversion system [24], [25]. The DC motor is directly coupled to the Double Fed Induction Generator (DFIG) and is powered by a chopper. The chopper is powered from the same DC bus as the DFIG rotor side inverter. This ensures that the delivered power from the rotor side of the DFIG through the Motor Side Converter (MSC) in hyper-synchronous mode will not increase the DC bus voltage and destroy the capacitors. Hence, we only need a simple three-phase diode-based rectifier as a Grid Side Converter (GSC). We use autotransformers for voltage adaptation as low as the DC machine maximum voltage $(250 \mathrm{~V})$. The stator of the DFIG is connecter to the grid. The main part of the generated power $P_{s}$ flows from the stator to the grid through the 13A autotransformer. To control both the 3-phases inverter and the DC chopper, we use a dSPACE DS1104 single board control solution with reprogrammed firmware.

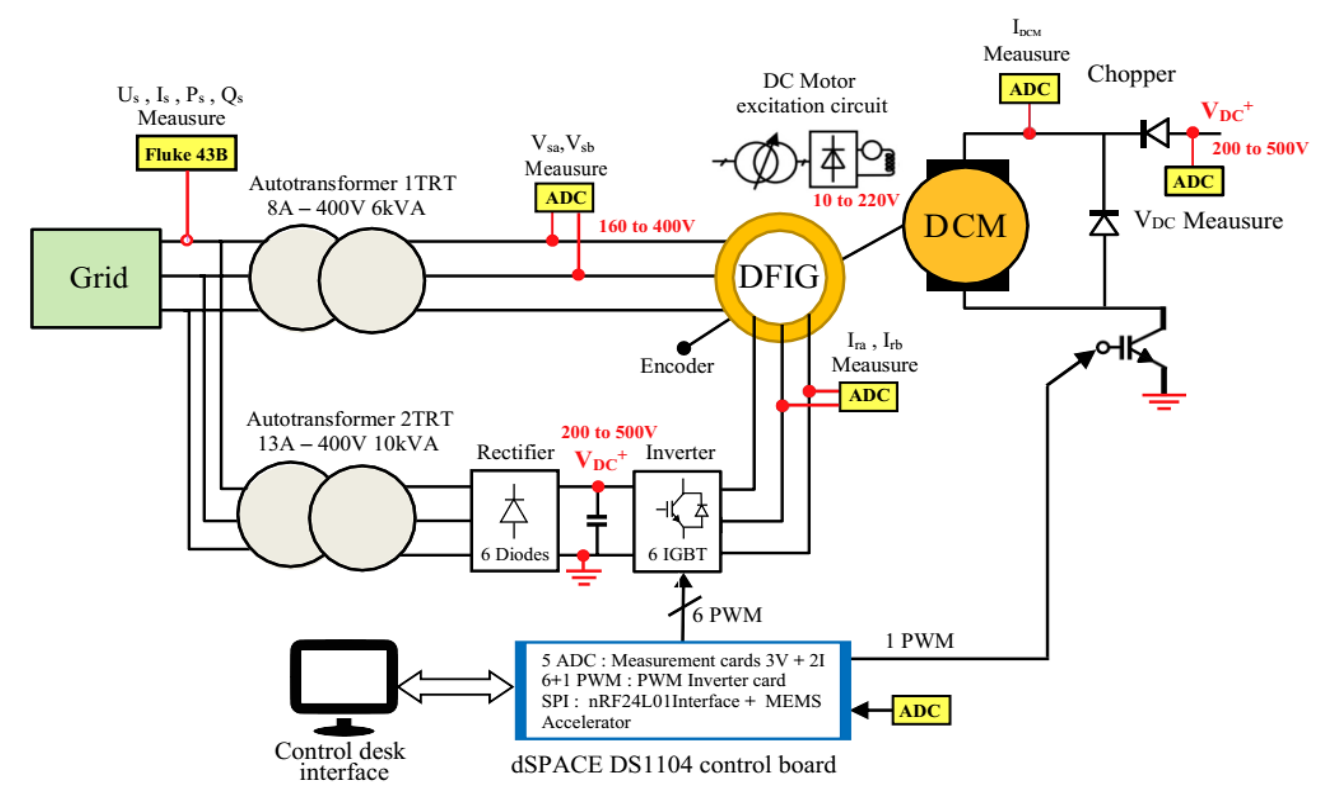

Figure 3. Experimental hardware structure of the wind turbine emulator based on a DFIG. 
Different wind profiles are applied through the control of the DC motor and an MPPT (Maximum Power Point Tracking) extraction algorithm allows the control of the speed of the Wind Turbine Emulator (WTE) in order to get the maximum power generated by the DFIG.

\subsubsection{Wind turbine emulator based on a Synchronous Generator}

A similar structure is used for the WTE based on a Synchronous Generator (SG) (Figure 4) [26], but we need back-to-back converters (MSC and GSC) between the grid and the stator of the SG. The Control Desk ${ }^{\mathrm{TM}}$ running on the host PC of the DS1104 permits the interaction with the embedded control program variables of the system in real time. This system is not yet fully operational; parameters identification and control parameters computation need to be performed.

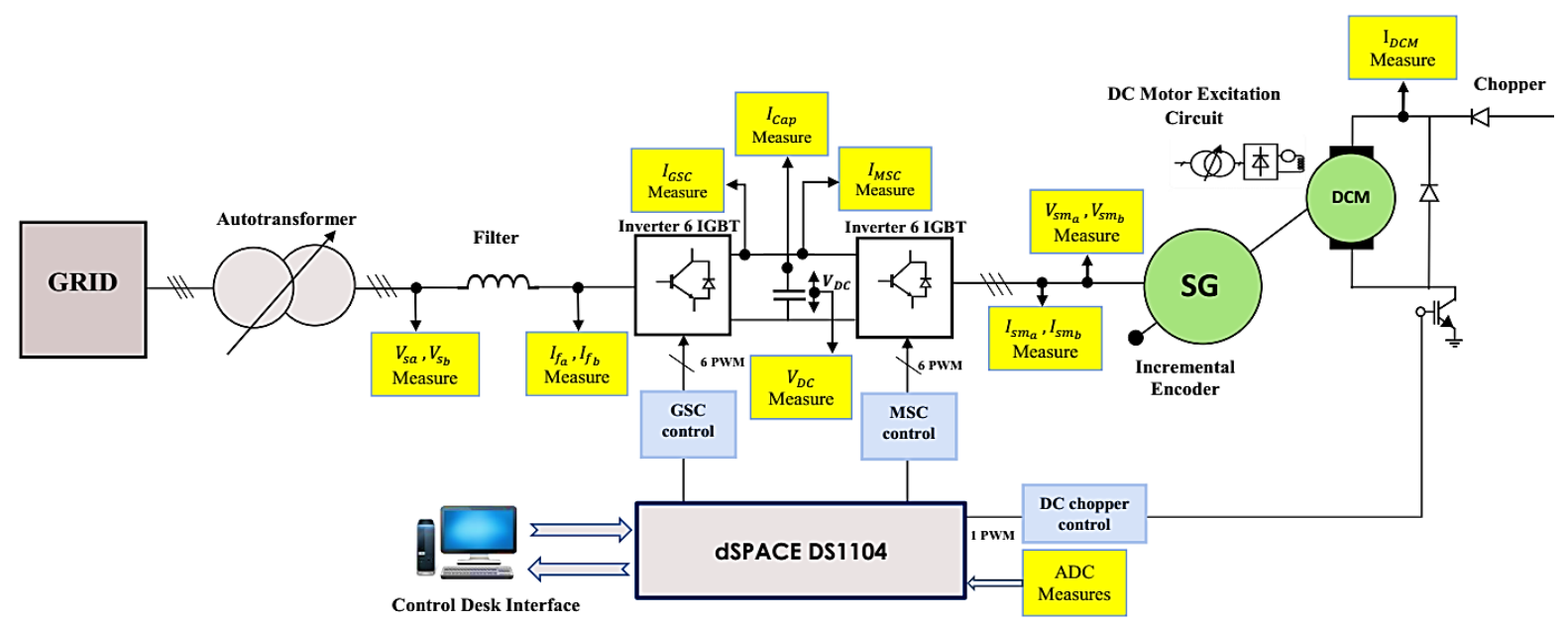

Figure 4. Experimental structure of the wind turbine emulator based on a SG

\subsubsection{Photovoltaic industrial micro power plant}

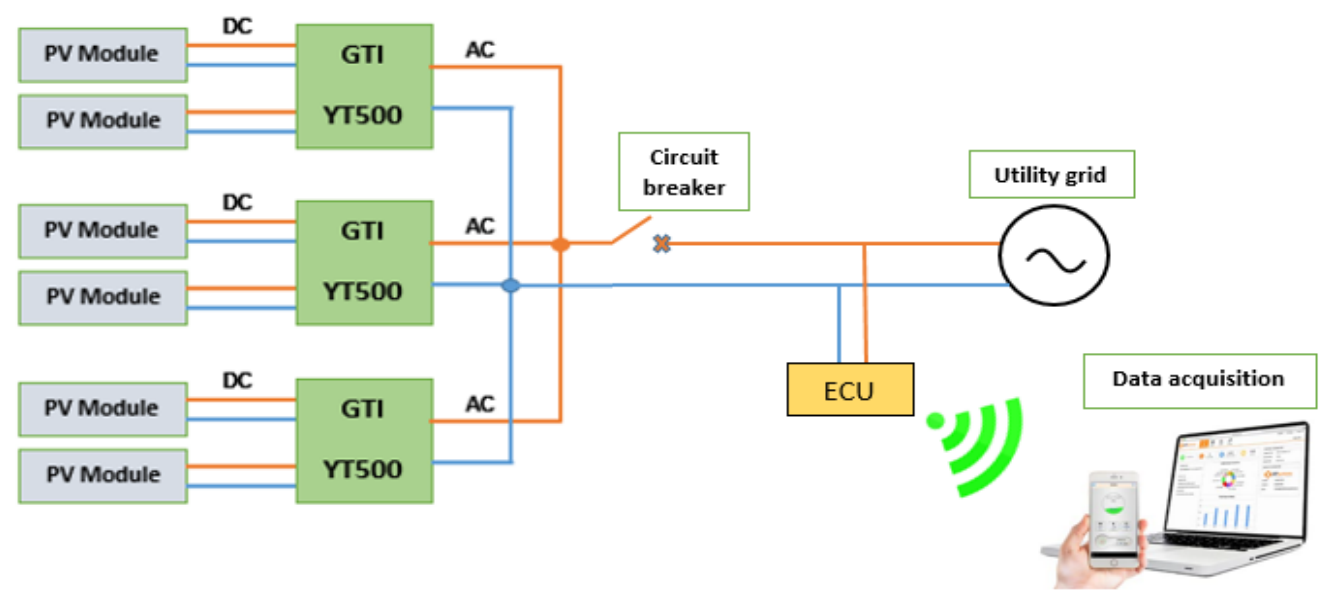

Figure 5. Experimental structure of the PV Grid Tie Inverter micro power plant.

Six PV panels (250 W for each one) are connected each two with one Grid Tie Inverter (GTI) YC500. Each GTI has two independent DC input with dedicated MPPT per input. The three GTI are connected in parallel to the grid via a circuit breaker. The Energy Communication Unit (ECU) uses PLC (power line carrier) to communicate with the GTI and sends data over the Wifi 
router to an external database (Figure 5). The ECU acts also as a local web server. A Raspberry $\mathrm{Pi} 3$ (RPi3) connected to the LAN reads the data of the generated power from the web server of the ECU and sends them to the Firebase Database (DB) each 5 minutes. This time can be adjusted.

\subsubsection{Photovoltaic self-made micro power plant}

In order to study our own implementation of a GTI, we choose to build it with two interleave step-up DC-DC choppers that extract the power form the PV. Then, the inverter stage synchronizes to the grid using a Zero Cross Detection algorithm and allows the injection of the reference active power. The reactive power can also be absorbed or generated from the grid or work at a unity power factor [27]. The control is done using TI Launchpad F28069M as shown in Figure 6. The communication to the DB is done with a Wemos ESP8266.

In order to produce the maximum power available (MPPT), or the exact amount of needed power or to shut down the power production, the control is taking the reference point from the DB.

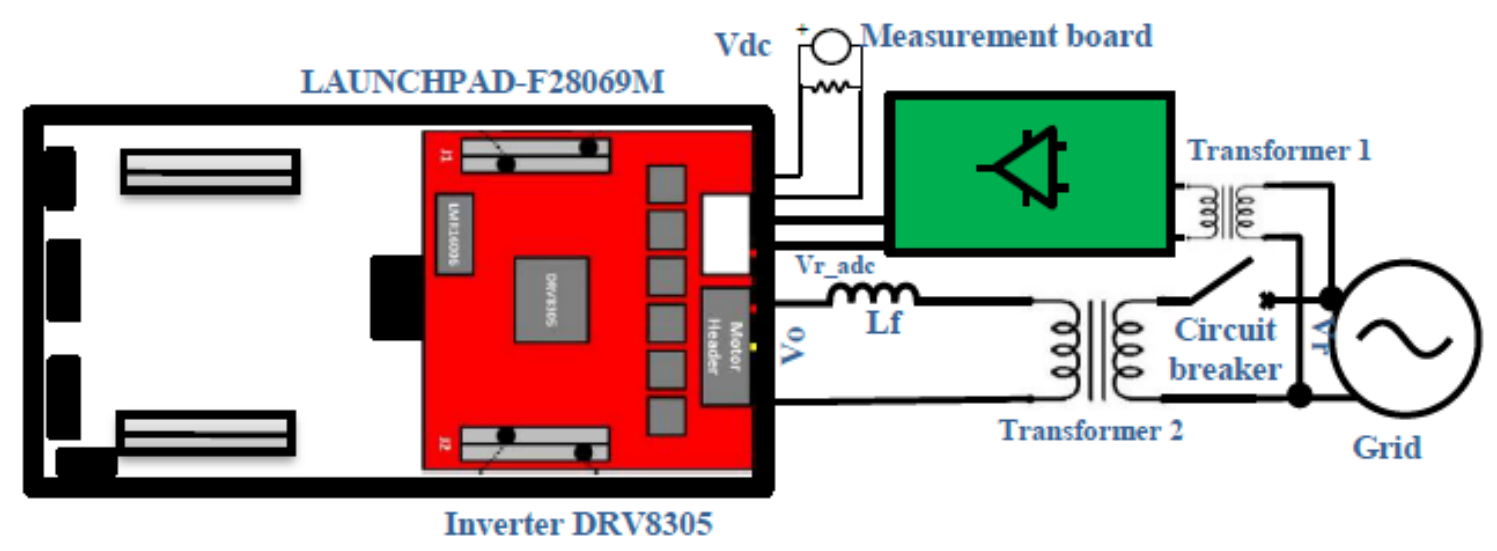

Figure 6. Experimental structure of the PV self-made micro power plant

\subsection{Simulated micro-power plants}

In parallel to the experimental prototypes, we created models of smart micro-power plants.

\subsubsection{Wind turbine generator micro-power plant model}

A simplified model of a DFIG expressed in a $(d-q)$ axis is used with flux vector control. This strategy allows the linearity between the rotor currents $\left(I_{q r}, I_{d r}\right)$ and the stator powers $\left(P_{s}, Q_{s}\right)$ of the DFIG [24].

Figure 7 shows the active and reactive power control diagram. Where $P_{\text {sref, }} Q_{\text {sref, }} I_{d r r e f}, I_{q r r e f}$, $V_{\text {drref }}$ and $V_{\text {qrref }}$ are the references of active power, reactive power, direct rotor current, quadrature rotor current, direct rotor voltage and quadrature rotor voltage respectively. $P_{s}, Q_{s}$, $I_{d r}, I_{q r}$ and $V_{s}$ are the active power, reactive power, direct rotor current, quadrature rotor current and stator voltage respectively. $L_{s}, L_{r}, M, R_{r}$ and sigma are the stator inductance, rotor inductance, mutual inductance, rotor resistance and insulation permittivity respectively. $W_{s}$ and $W_{r}$ are the stator pulsation $\left(2 \pi f_{s}\right)$ and the slip pulsation respectively.

To extract the maximum power available, we used an MPPT algorithm that calculates the optimum mechanical speed $W_{m_{-}}$opt of the DFIG and then generates the active power reference 
$P_{\text {sref }}$ thanks to a PI controller as shown in Figure 8. Where lambda_opt is the optimal relative speed, $G$ is the gearbox ratio, $R$ is the pale radius, $W_{s p}$ is the wind speed and $W_{m}$ is the mechanical speed of the DFIG.

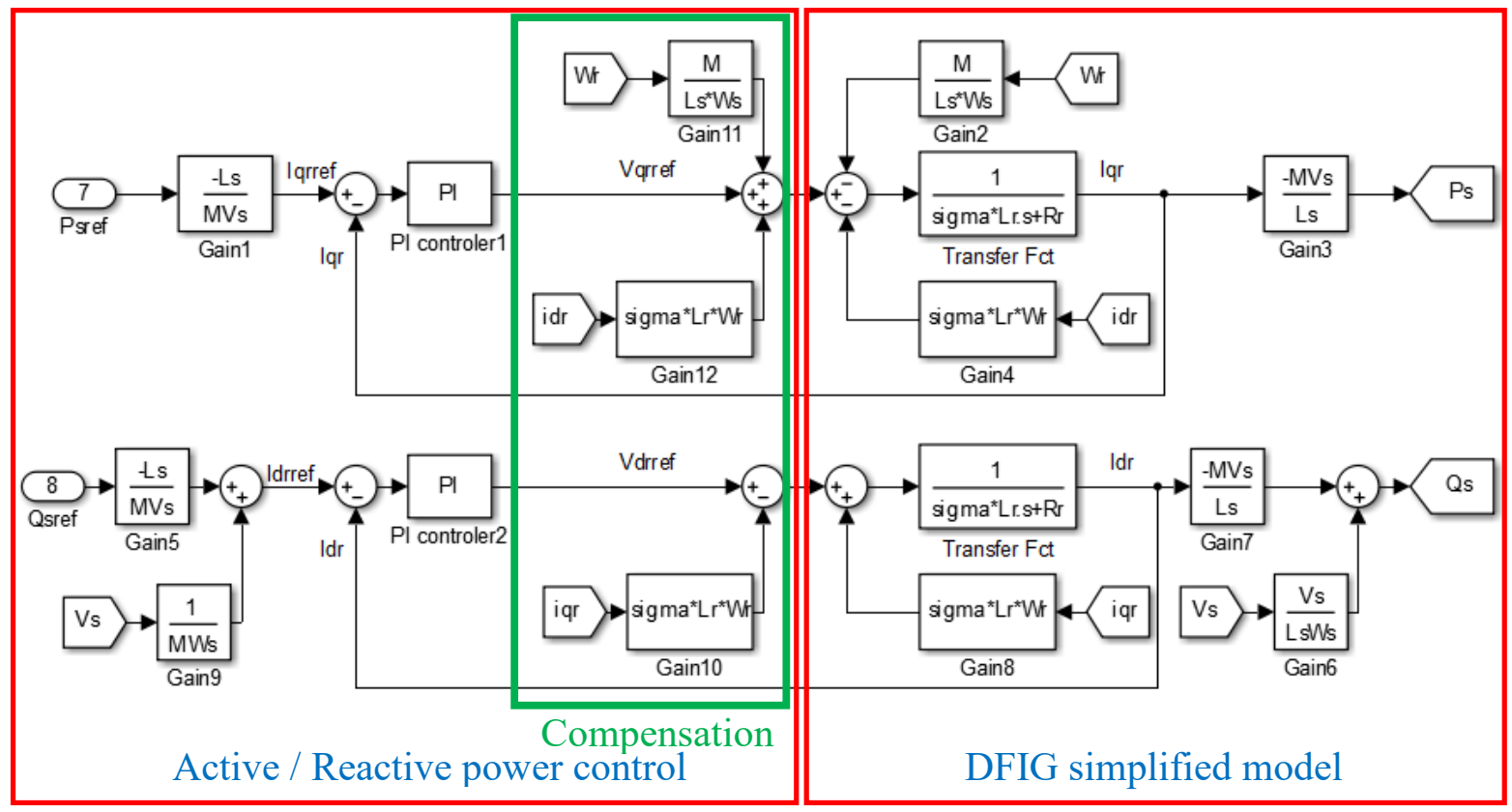

Figure 7. DFIG active and reactive power control diagram

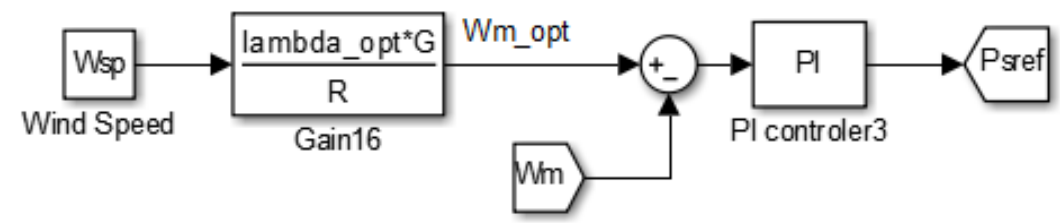

Figure 8. MPPT Diagram of the wind turbine generator

Figure 9 shows the maximum active power (blue curve) extracted from the wind turbine generator micro-power plant model when applying a wind profile shown by the green curve.

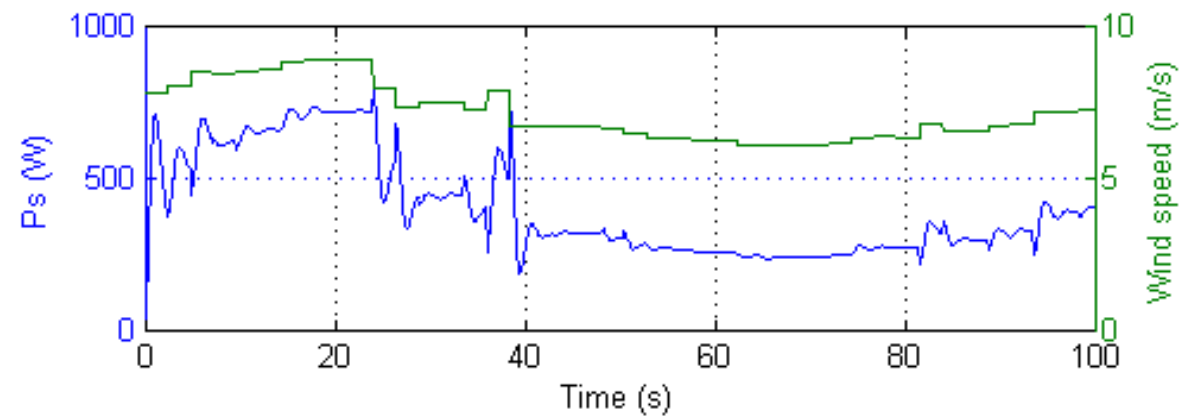

Figure 9. Simulated wind power 


\subsubsection{Photovoltaic micro-power plant model}

A PV panel is modelled as a current source in parallel to a diode and a parallel resistance $R_{p}$. All are in series with a resistance $R_{s}$. The output current $I_{p v}$ of a PV panel is calculated as fallow [14], [24]:

$$
I_{p v}=I_{p h}-I_{o}\left(\frac{e^{q\left(V+I_{p v} R s\right)}}{a k T}-1\right)-\frac{V+I_{p v} R_{s}}{R_{p}}
$$

Where $I_{p h}$ is the photon current, $I_{o}$ is the Diode saturation current, $q$ is the electron's charge, $V$ is the PV voltage, $T$ is the temperature, $k$ is the constant of Boltzmann and $a$ is the quality factor. For a specific temperature and irradiance, the generated power of a PV panel varies in function of the voltage as shown in Figure 10. To extract the maximum power available, an MPPT algorithm searches the appropriate voltage that fulfils the equation $d P / d V=0$. Where $P$ is the generated power.

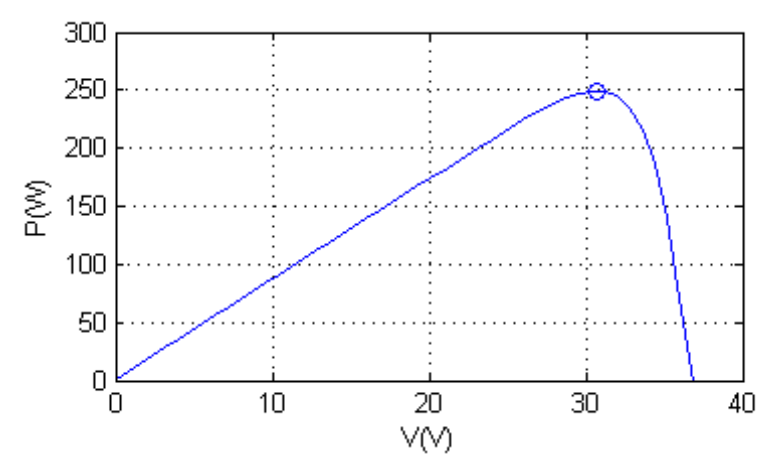

Figure 10. The variation of the PV power in function of the voltage

Figure 11 shows the maximum active power (blue curve) extracted from the PV micro-power plant model when applying irradiance profile shown by the green curve. In this simulation, the temperature supposed constant at $25^{\circ} \mathrm{C}$.

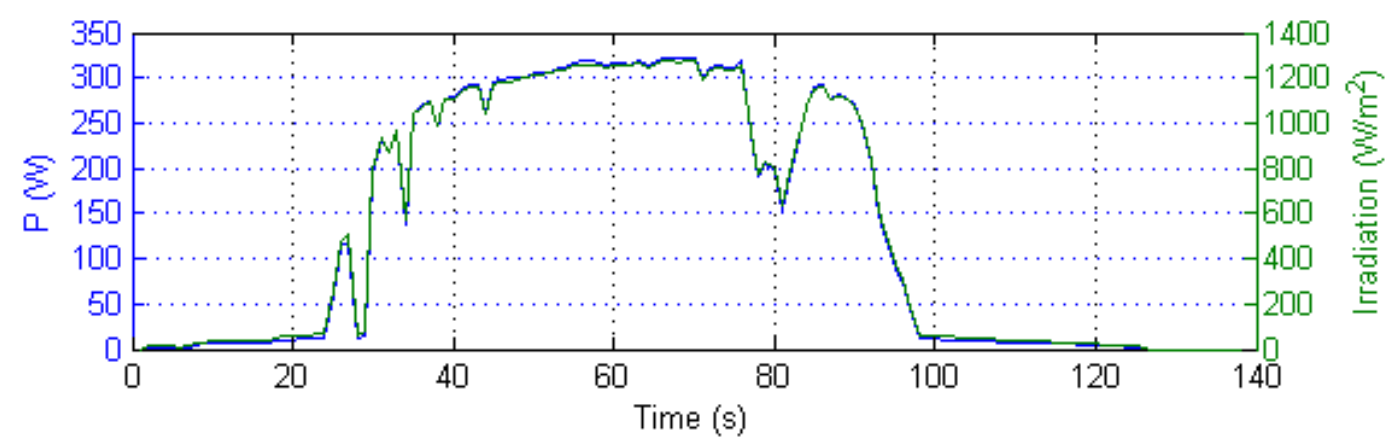

Figure 11. Simulated solar power

\subsection{Emulating the power grid}

For this step, we emulate the high-voltage utility grid by a 5-buses power grid [28] (Figure 12) running in real time on the RPi3. It contains two Generator buses (nodes). SOUTH is a PV bus and NORTH is the Slack bus. There are three consumption nodes (ELM, LAKE, and MAIN). 
To compute the power flow through the grid and the voltage at all the buses, we implemented the Load Flow (LF) program of a Lab developed program [28] on the RPi3. In addition, the Transient Stability (TS) program is also implemented and adapted to the RPi3. Moreover, we implemented two power system stabilizers (PSS) to ensure the stability of the system. The first one is an Automatic Voltage Regulator (AVR) to stabilize the magnitude of the voltage and the second one is the speed governor to stabilize the speed of the power plant SG.

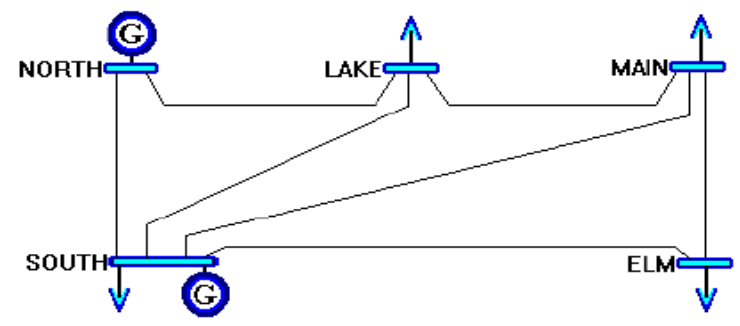

Figure 12. 5-buses power system [28]

The mathematical equations and the power system modelling for LF and TS studies are found in [28]. The Runge-Kutta 4 and Gauss-Seidel are the numerical methods implemented for the iterative calculations of TS and LF respectively. The system of equations to be solved for TS studies to express the dynamic behavior of a SG is [28]:

$$
\left\{\begin{array}{l}
\frac{d \delta}{d t}=\omega-\omega_{s} \\
\frac{d^{2} \delta}{d t^{2}}=\frac{\omega_{s}}{2 H}\left(P_{m}-P_{e}-D \frac{d \delta}{d t}\right)
\end{array}\right.
$$

Where $\delta$ is the internal angel, $\omega$ is the rotor speed, $\omega_{s}$ is the synchronous speed, $P_{m}$ is the mechanical power of the turbine, $P_{e}$ is the electrical power, $H$ is the inertia moment, and $D$ is the damping for each generator.

\subsection{Communication protocols and experimental issues}

To study the impact of integrating renewable energy MPP on the stability of the 5-buses power grid and to analyze their mutual interaction in grid-connected mode, the smart prototypes of MPP should communicate to the DB in order to send information about their actual production and receive orders to inject to the grid the exact power needed, not more and not less. This helps us to control the smart MPP and to manage the power produced from renewable energies. For that, we implemented routines on the $\mathrm{RPi} 3$ to communicate with the $\mathrm{DB}$ in order to receive the generated power from the experimental MPP and to send orders for the reference power. Reading data and sending orders are done every 5 seconds. We developed an Android application (Figure 13) to check for any update in the DB and displays data; it is available on:

https://play.google.com/store/apps/details?id=com.embesystems.microplants.

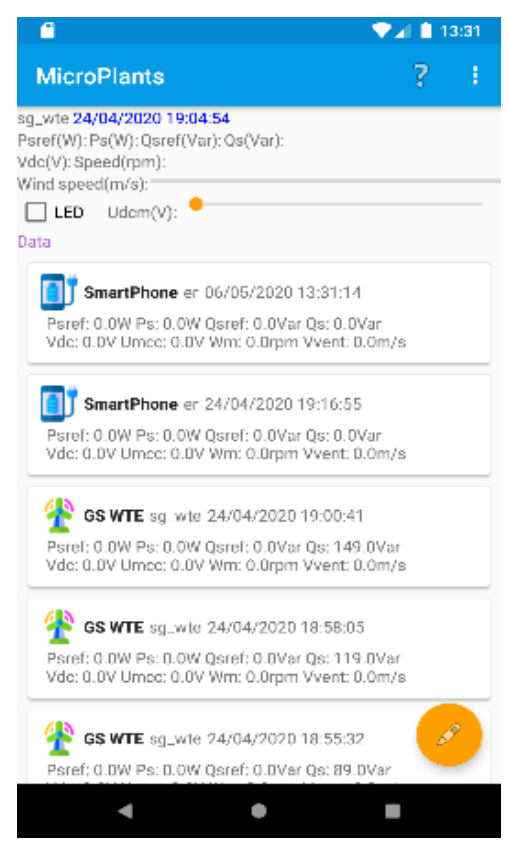

Figure 13. MicroPlants Android application 
Figure 14 illustrates the communication interactions between the MPP, emulated power grid and the external supervisor (Android application or PC) with the DB thanks to Wi-Fi connected microcontrollers ESP8266.

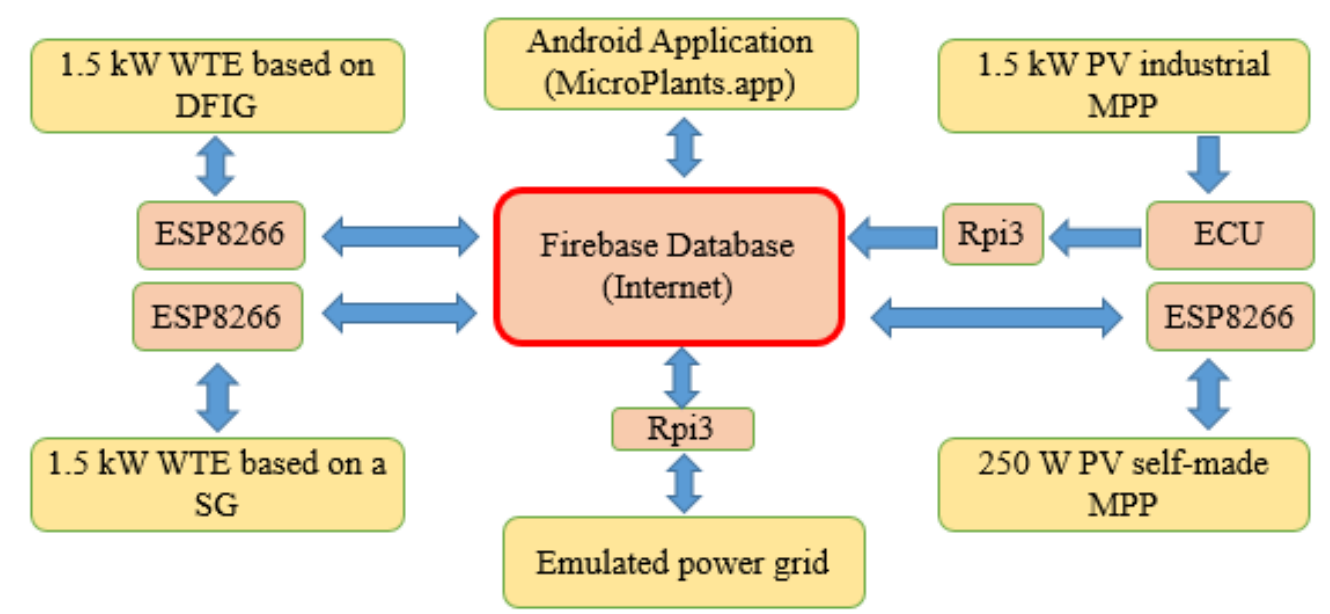

Figure 14. Communication interactions between the MPP, emulated power grid and the Android application with the DB.

We are still facing some experimental issues: The WTE based on DFIG is operational but it is not yet communicating to the DB. The WTE based on a SG is already communicating to the DB thanks to the microcontroller ESP8266, but it is not yet fully operational, we have some issues when controlling the SG. The $1.5 \mathrm{~kW}$ PV industrial MPP is only sending data thanks to the second RPi3 that reads data from the server of the ECU and send them to the DB, but this MPP cannot receive orders of the needed reference power, because the GTI YC500 produces always the maximum power thanks to its MPPT internal algorithms. The $250 \mathrm{~W}$ PV self-made MPP however will send and receive orders to / from the DB thanks to the microcontroller ESP8266 to produce the needed power, but this experimental bench is still under progress.

To deal with the communication issues of the experimental prototypes and the early stage of development of the MPP, we proceed by collecting experimental data of both PV and WTE based on DFIG micro-power plants in a laptop. The collected data in the RPi3, will be used by the LF and TS programs to be injected in the 5-buses power grid.

In this paper, four cases are presented: the first is when the 5-buses power grid functions without injecting the power of the MPP, the second is when we inject only the power of the PV micropower plant at ELM bus, the third is when we inject only the power of the WTE based on a DFIG at LAKE bus, and the last case is when we inject the power of both PV and WTE micropower plants in the corresponding buses. In the cases 1, 2, 3 and 4, the installed capacity from renewable energy MPP is $0 \%, 20 \%, 35 \%$ and $55 \%$ of the total production respectively. In all these cases, we consider all other loads constant. In addition, the data are received in Watt, and then transformed to per-unit (pu) in order to adapt them with LF and TS calculations that are in $\mathrm{pu}$. The NORTH generator curves are represented by the blue color and the SOUTH ones are represented by the red color in the following figures. 


\section{RESULTS AND DISCUSSIONS}

The characteristics of the two SG are presented in Table A.1. The TS and LF calculations are performed every $1 \mathrm{~ms}$ to get the new values of the generated power, bus voltage, speed and internal angles of both SG. The AVR is called every $2 \mathrm{~ms}$ whereas the speed governor loop is performed every $10 \mathrm{~ms}$. Table A. 2 shows the initial data for TS calculations. They are obtained from a previous LF simulation, in steady state conditions, before starting the TS simulation. Figure 15 and Figure 16 show the AVR and the speed governor loops respectively; Where $E_{g 0}$ and $\mathrm{P}_{\mathrm{m} 0}$ are the nominal values of e.m.f and mechanical power respectively. $E_{\text {g.ref }}$ and $P_{m . r e f}$ are the reference values for the e.m.f and the mechanical power respectively. $E_{g}, I_{g}, V$ and $Y_{g}$ are the e.m.f, current, voltage and admittance of the SG respectively. $K_{p}$ and $K_{i}$ are the proportional and integral coefficients of the AVR or the speed governor.

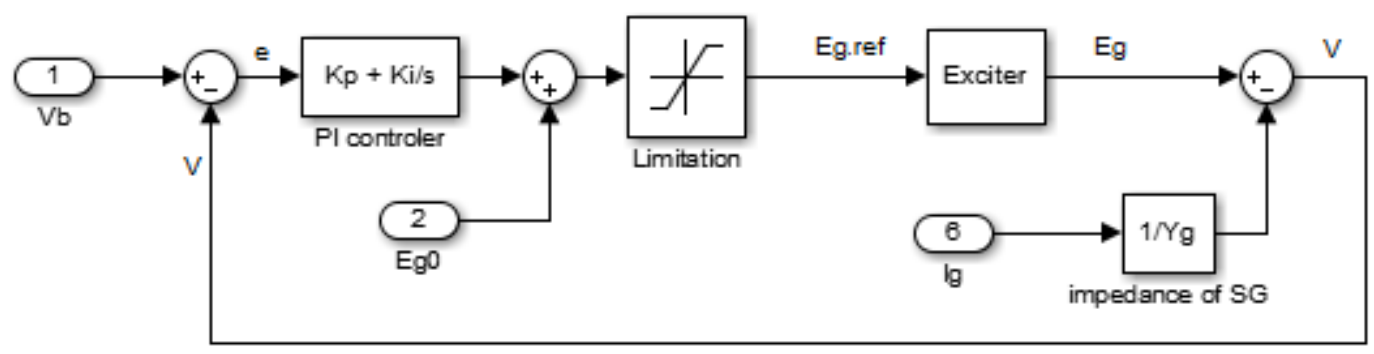

Figure 15. AVR loop for both generators

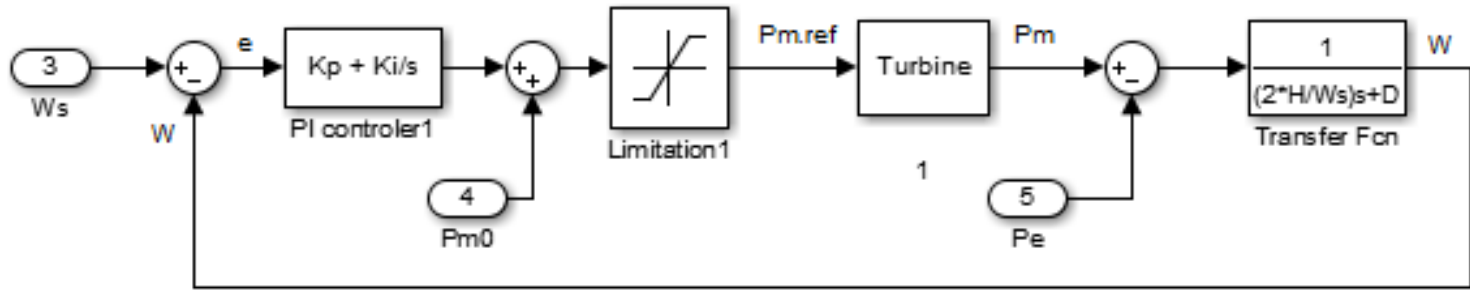

Figure 16. Speed Governor loop for both generators

\subsection{Case 1}

In this case, the 5-buses power grid are operating with no power injected from the MPP. The Figure 17 shows the variation of the electrical and mechanical quantities (Voltage, internal angle, speed and power) of both SG. The total active power production is $1.6957 \mathrm{pu}(0.4 \mathrm{pu}$ from SOUTH and $1.2957 \mathrm{pu}$ from NORTH). We see that, all the electrical and mechanical quantities are constant in steady state. This is explained by the non-integration of MPP and that there is no modification or faults in the power network. 

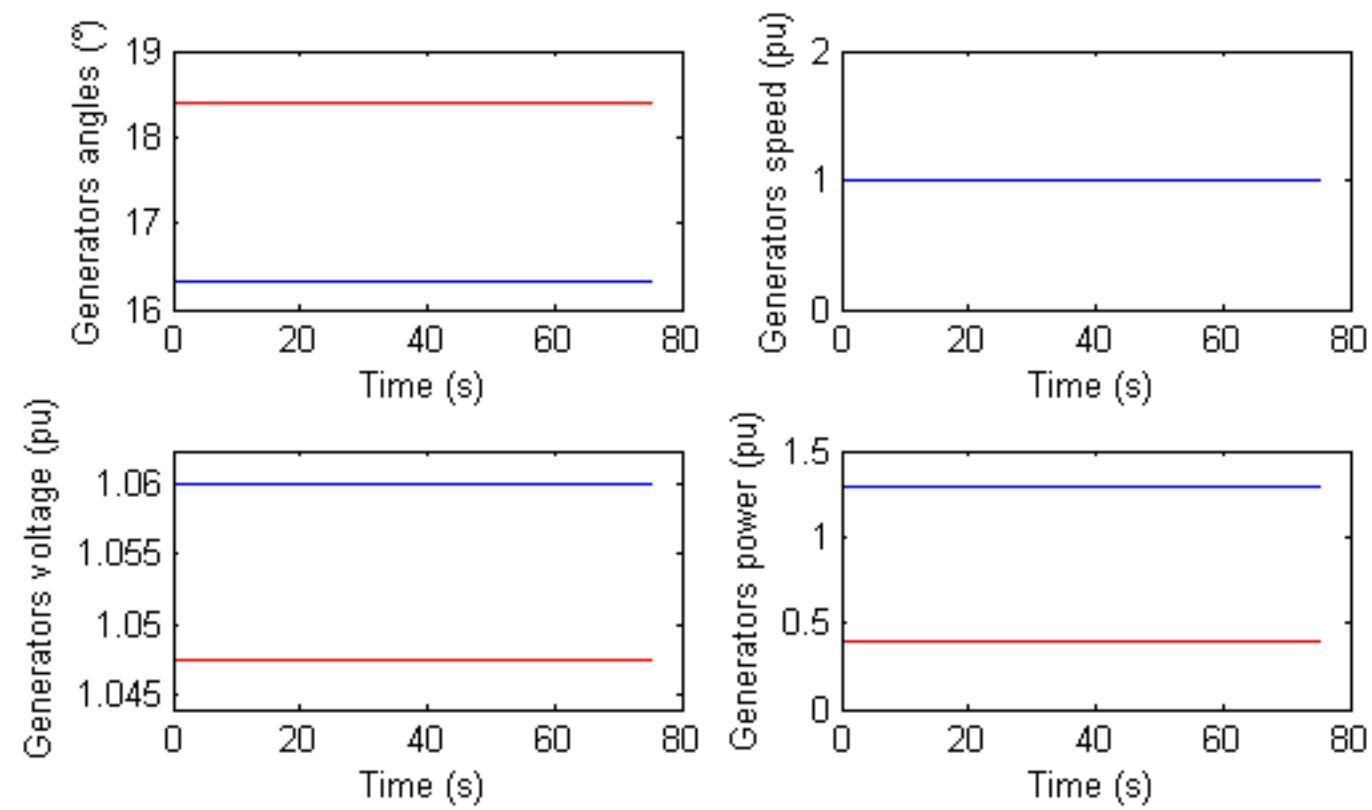

Figure 17. SG electrical and mechanical variables

\subsection{Case 2}

In this case, the PV MPP starts injecting power in the 5-buses power grid at ELM bus after $\mathrm{t}=10 \mathrm{~s}$. Figure 18 shows the variation of the PV power. A routine is added to the TS program to read these data from a file and to inject them in the 5-buses power grid as additional positive load that varies with time (positive values are for generated power).

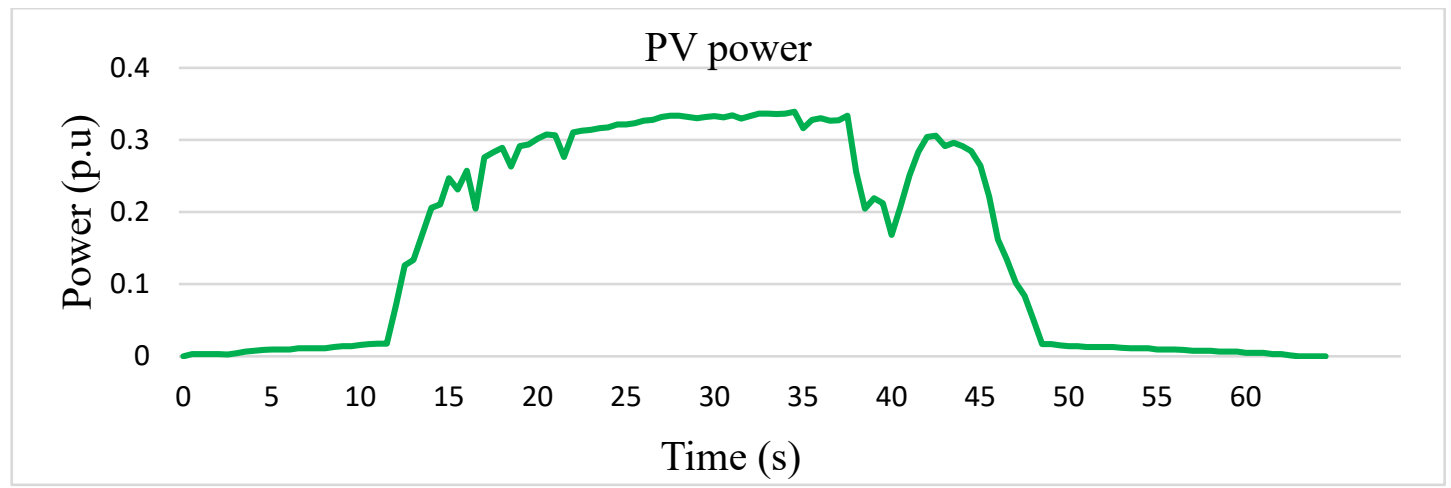

Figure 18. The power of the PV prototype

Figure 19 shows the variation of the electrical and mechanical quantities of both generators. We see that, when injecting the PV power in ELM bus, both generators will be affected due to the interconnection of the grid. A mismatch between the consumption and the production happened. Thus, both generators accelerate. Thanks to the PSS, the AVR and the speed governor that control respectively the e.m.f and the mechanical power of both SG, the generated power from the non-renewable sources is reduced. This fast acting makes the voltage and the speed come back to their nominal values spontaneously after each increase or decrease in the injected power. In addition, it makes the internal angels of both generators stay in the stability $\operatorname{limit}\left(\delta<90^{\circ}\right)$. 

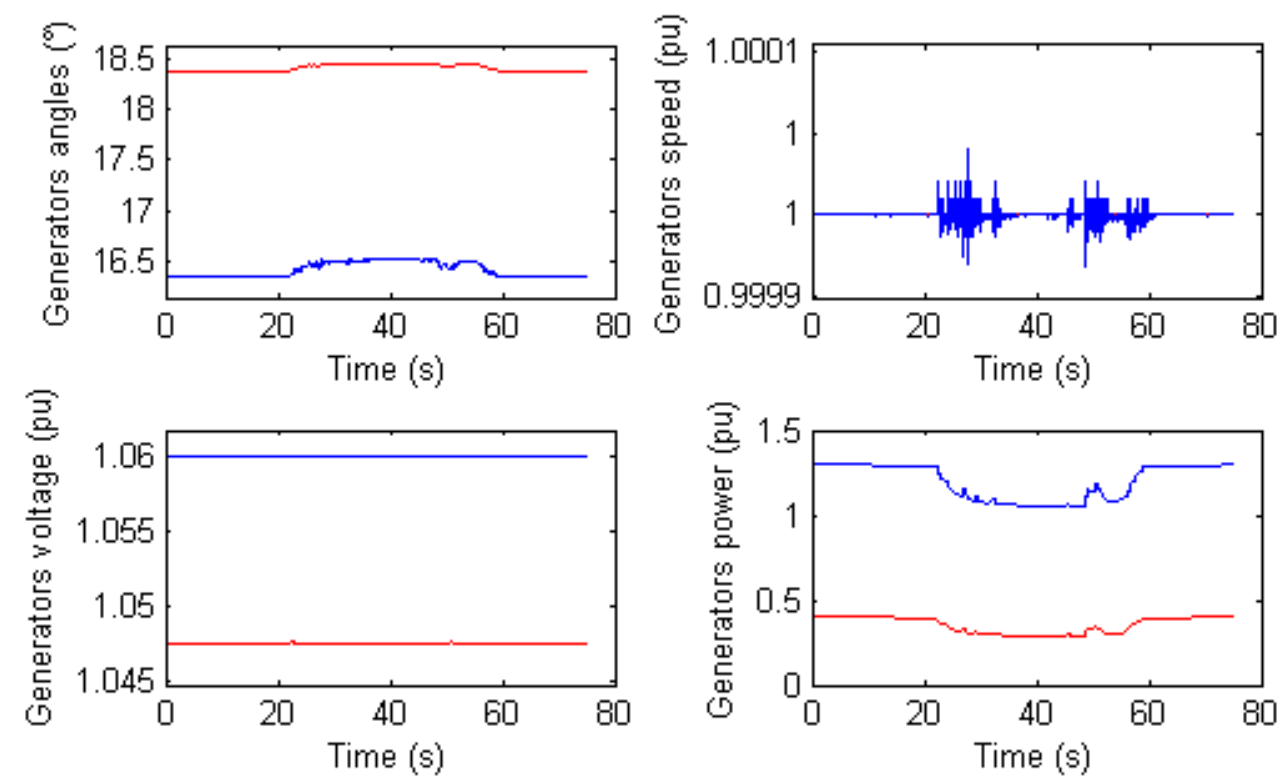

Figure 19. SG electrical and mechanical variables, $\mathrm{PV}$ power is integrated

\subsection{Case 3}

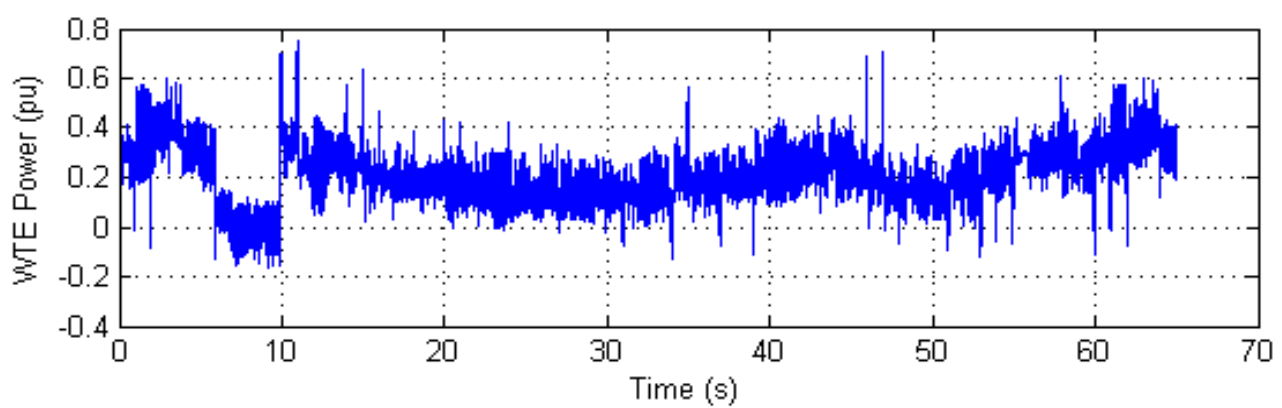

Figure 20. The DFIG-based WTE generated power

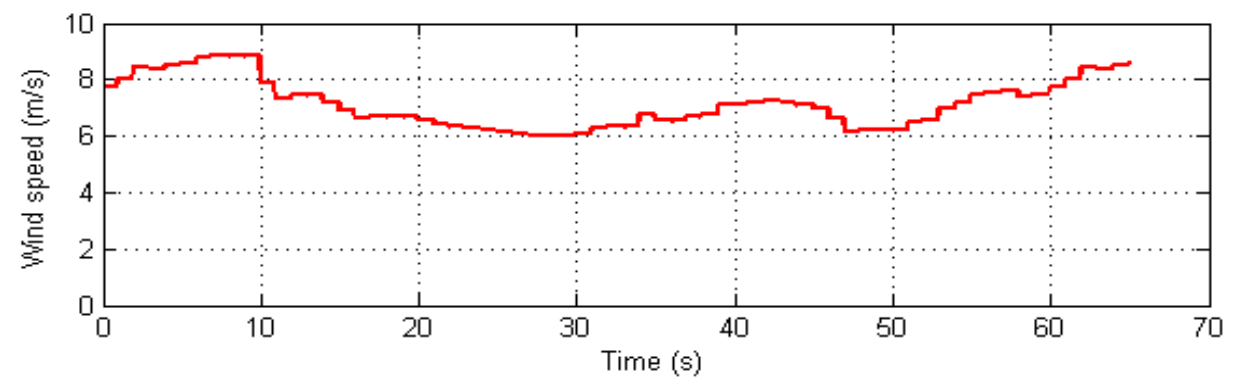

Figure 21. Wind profile used for WTE experiments

In this case, the DFIG-based WTE micro-power plant starts injecting its power at the LAKE bus. Figure 20 shows the variation of the injected power in pu which is more fluctuant compared to the injected PV power. This power is obtained with certain conditions: The wind profile (Figure 21) should be more than $5 \mathrm{~m} / \mathrm{s}$ and less than $9 \mathrm{~m} / \mathrm{s}$ [24]. which is equivalent to 1300 
rpm and $1800 \mathrm{rpm}$ for the WTE respectively. If, due to the wind profile, the control variable (voltage of the DC motor) exceeds its limits, the driven torque is no more controlled and we stops the power generation. This is shown between $5 \mathrm{~s}$ and $10 \mathrm{~s}$.
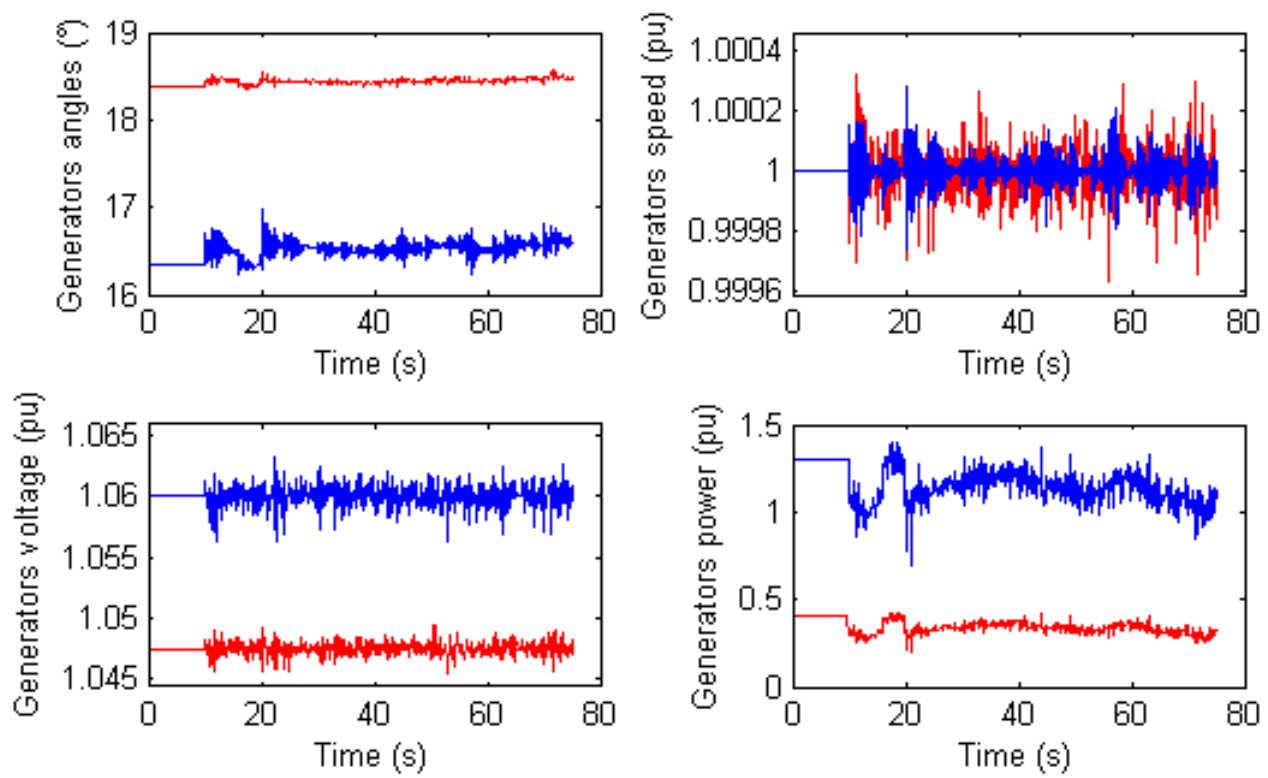

Figure 22. SG electrical and mechanical variables, WTE power is injected

In this third case study, the mechanical and the electrical quantities are more affected by the high fluctuation of the WTE power (Figure 22) compared to the PV power of case 2 but, once again, the system is well controlled thanks to the PSS.

\subsection{Case 4}
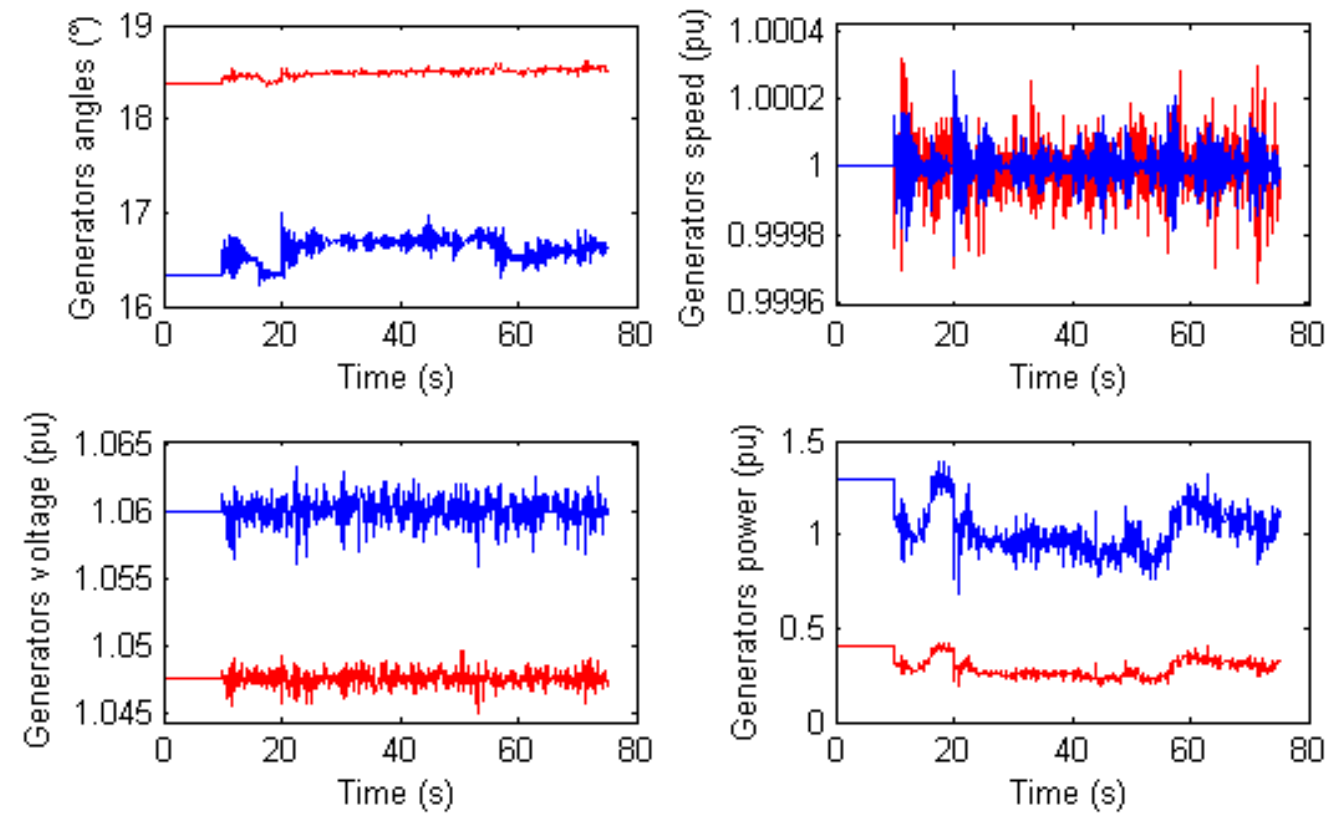

Figure 23. SG electrical and mechanical variables when both PV and WTE are considered 
In this last case study, the data of both PV and WTE are used for a power injection at ELM and LAKE buses respectively from $\mathrm{t}=10 \mathrm{~s}$. It is clear that the disturbances generated by the intermittent injected powers propagate rapidly to the grid connected affecting both generators as shown in Figure 23. In addition, the PSS present a fast reaction to the power mismatch making voltage and speed remaining to their nominal values for each disturbance.

Comparing case 2, 3 and 4, we conclude that, it is not the quantity of the injected power that makes important disturbances, but its variation rate. We see in case 4 that the disturbances are the same as case 3. Indeed, the generated power from the two SG is reduced much more in the case 4 compared to the case 2 and 3 .

\title{
4. CONCLUSION
}

This paper presents the impact of integrating renewable energy MPP on power grids over Africa. Special designed experimental prototypes of renewable energy MPP have been used in this study. As there is less wind in Algeria, experimental emulations are used to emulate the wind turbines based on a DFIG or based on a SG. Corresponding wind profiles of moderate speeds are used.

In addition, simulated models that reflect the same behaviour as the experimental ones are presented. Communication protocols between all the MPP are done thanks to a developed firebase database and micro-controller (Wemos ESP8266) programs. An android application that plays the role of an external supervisor communicates with the DB and displays the data flow in real time. It was shown that the integration of distributed renewable energy production thanks to MPP will enforce the weakness of power grids in Africa. It reduces the generated power from the conventional generators, hence, reducing the consumption of fuel, minimizing the GHE, and reduce many types of losses. The drawbacks are the negative impact on the quality of service and on the stability of the power grid due to the intermittent availability of the sources.

With an appropriate control of the e.m.f. and the mechanical power of the conventional generators, we can reduce the apparatus and the disturbances results from the renewable MPP. A proper communication between the MPP, the power plants and the grid system operator will help in anticipating the control.

Due to the fact that apparatus and disturbances propagate rapidly in the connected network, the control and management of the generated power from renewable sources are very important to avoid fragilizing the power grid and to keep the system working at optimal efficiency.

\section{ACKNOWLEDGEMENT}

This study is financially supported by the German Federal Ministry of Education and Research (BMBF) via its project management agency DLR, under the project "Water and Energy Security in Africa (WESA-ITT)". This work is also supported by the Direction Generale de la Recherche Scientifique et du Developpement Technologique (DG RSDT) of Algeria.

\author{
ABBREVIATIONS \\ MPP: Micro-Power Plants \\ AfDB: African Development Bank
}


PENREE: The Algerian Renewable Energy Development and Energy Efficiency Program PV: Photovoltaic

EST: Energy Storage Technologies

GHE: Green Houses Emissions

WTE: Wind Turbine Emulator

DFIG: Double Fed Induction Generator

SG: Synchronous Generator

MSC: Motor Side Converter

GSC: Grid Side Converter

MPPT:Maximum Power Point Tracking

DB: Database

RPi3: Raspberry Pi3

ECU: Energy Communication Unit

GTI: Grid Tie Inverter

$P_{\text {sref: }}$ The reference active power

$Q_{\text {sref: }}$ The reference reactive power

$I_{\text {drref: }}$ The reference direct rotor current

$I_{\text {qrref: }}$ The reference quadrature rotor current

$V_{d r r e f}$. The reference direct rotor voltage

$V_{\text {qrref: }}$ The quadrature rotor voltage

$P_{s}: \quad$ The active power

$Q_{s}: \quad$ The reactive power

$I_{d r}: \quad$ The direct rotor current

$I_{q r}: \quad$ The quadrature rotor current

$V_{s}: \quad$ Stator voltage

$L_{s}: \quad$ Stator inductance

$L_{r}: \quad$ Rotor inductance

$M$ : Mutual inductance

$R_{r}: \quad$ Rotor resistance

sigma: Insulation permittivity

$W_{s}$ : Stator pulsation

$f_{s}: \quad$ Stator frequency

$W_{r}$ : Slip pulsation

$W_{m}$ opt: Optimum mechanical speed

lambda_opt: Optimal relative speed

$G: \quad$ Gearbox ratio

$R: \quad$ Pale radius,

$W_{s p}: \quad$ Wind speed

$W_{m}$ : Mechanical speed of the DFIG

$R_{p}$ : $\quad$ Parallel resistance

$R_{s}$ : $\quad$ Serial resistance

$I_{p v}$ : The output current of a PV panel

$I_{p h}: \quad$ The photon current

$I_{o}: \quad$ The Diode saturation current

$q$ : The electron's charge

$V: \quad$ The voltage

$T: \quad$ The temperature

$K \quad$ The constant of Boltzmann

$a: \quad$ The quality factor.

$P$ : $\quad$ The PV generated power 
PSS: Power System Stabilizers

AVR: Automatic Voltage Regulator

e.m.f: Electromotive Force

LF: Load Flow

TS: Transient Stability

$\delta: \quad$ The internal angle of the Synchronous Generator

$\omega: \quad$ The rotor speed of the Synchronous Generator

$\omega_{s}$ : The synchronous speed

$P_{m}$ : The mechanical power of the turbine

$P_{\operatorname{m} m a x}$ The maximum mechanical power of the turbine

$P_{m .0}$ : The nominal value of the mechanical power

$P_{m . r e f}$ : The reference value of the mechanical power

$P_{e:} \quad$ The electrical power

$P_{g}: \quad$ The generated power

$P_{L}: \quad$ The consumed power

$V_{b}$ : The nominal value of the bus voltage

$E_{\text {g.max }}$ The maximum electromotive force

$E_{g}: \quad$ The electromotive force

$E_{g .0}:$ The nominal value of the e.m.f

$E_{\text {g.ref: }}$ The reference value of the e.m.f

Ig: The generated current of the SG

$Y_{g}: \quad$ The admittance of the SG

$K_{p}$ : The proportional coefficient for the AVR or for the speed governor respectively

$K_{i}: \quad$ The integral coefficient for the AVR or for the speed governor respectively

$e: \quad$ The controller input error (voltage / speed)

$H$ : The inertia moment

$D: \quad$ The damping

$R: \quad$ The resistance

$X_{d}$ : The transient reactance

\section{REFERENCES}

[1] "Population of Africa (2020) - Worldometer." https://www.worldometers.info/worldpopulation/africa-population/ (accessed Feb. 26, 2020).

[2] N. S. Ouedraogo, "Modeling sustainable long-term electricity supply-demand in Africa," Appl. Energy, vol. 190, pp. 1047-1067, Mar. 2017, doi: 10.1016/j.apenergy.2016.12.162.

[3] S. Szabó, K. Bódis, T. Huld, and M. Moner-Girona, "Energy solutions in rural Africa: mapping electrification costs of distributed solar and diesel generation versus grid extension," Environ. Res. Lett., vol. 6, no. 3, p. 034002, Jul. 2011, doi: 10.1088/17489326/6/3/034002.

[4] M. A. Cole, R. J. R. Elliott, G. Occhiali, and E. Strobl, "Power outages and firm performance in Sub-Saharan Africa," J. Dev. Econ., vol. 134, pp. 150-159, Sep. 2018, doi: 10.1016/j.jdeveco.2018.05.003.

[5] N. S. Ouedraogo, "Energy consumption and economic growth: Evidence from the economic community of West African States (ECOWAS)," Energy Econ., vol. 36, pp. 637-647, Mar. 2013, doi: 10.1016/j.eneco.2012.11.011.

[6] N. S. Ouedraogo, "Energy consumption and human development: Evidence from a panel cointegration and error correction model," Energy, vol. 63, pp. 28-41, Dec. 2013, doi: 10.1016/j.energy.2013.09.067. 
[7] J. Li, P. Liu, and Z. Li, "Optimal design and techno-economic analysis of a solar-windbiomass off-grid hybrid power system for remote rural electrification: A case study of west China," Energy, vol. 208, p. 118387, Oct. 2020, doi: 10.1016/j.energy.2020.118387.

[8] H. S. Farmad and S. Biglar, "Integration of demand side management, distributed generation, renewable energy sources and energy storages," in CIRED 2012 Workshop: Integration of Renewables into the Distribution Grid, Lisbon, Portugal, 2012, pp. 166166. doi: 10.1049/cp.2012.0784.

[9] L. Montuori, M. Alcázar-Ortega, C. Álvarez-Bel, and A. Domijan, "Integration of renewable energy in microgrids coordinated with demand response resources: Economic evaluation of a biomass gasification plant by Homer Simulator," Appl. Energy, vol. 132, pp. 15-22, Nov. 2014, doi: 10.1016/j.apenergy.2014.06.075.

[10] B. Park and J. Hur, "Spatial prediction of renewable energy resources for reinforcing and expanding power grids," Energy, vol. 164, pp. 757-772, Dec. 2018, doi: 10.1016/j.energy.2018.09.032.

[11] "Roadmap to the New Deal on Energy for Africa: An analysis of optimal expansion and investment requirements." Multiconsult, Jun. 15, 2018. Accessed: Jul. 07, 2021. [Online]. Available: https://africa-energy-portal.org/sites/default/files/201810/lu313516crr2.pdf

[12] M. Bouznit, M. del P. Pablo-Romero, and A. Sánchez-Braza, "Measures to Promote Renewable Energy for Electricity Generation in Algeria," Sustainability, vol. 12, no. 4, p. 1468, Feb. 2020, doi: 10.3390/su12041468.

[13] P. Basak, S. Chowdhury, S. Halder nee Dey, and S. P. Chowdhury, "A literature review on integration of distributed energy resources in the perspective of control, protection and stability of microgrid," Renew. Sustain. Energy Rev., vol. 16, no. 8, pp. 5545-5556, Oct. 2012, doi: 10.1016/j.rser.2012.05.043.

[14] D. Çelik and M. E. Meral, "A novel control strategy for grid connected distributed generation system to maximize power delivery capability," Energy, vol. 186, p. 115850, Nov. 2019, doi: 10.1016/j.energy.2019.115850.

[15] T. L. Alumona, O. Nwosu Moses, A. O. Ezechukwu, and C. Jonah, "Overview Of Losses And Solutions In Power Transmission Lines," Network and Complex Systems, vol. 4, no. 8, 2014.

[16] P. Dalwadi, V. Shrinet, C. R. Mehta, and P. Shah, "Optimization of solar-wind hybrid system for distributed generation," in 2011 Nirma University International Conference on Engineering, Ahmedabad, Gujarat, India, Dec. 2011, pp. 1-4. doi: 10.1109/NUiConE.2011.6153300.

[17] H. A. Behabtu et al., "A Review of Energy Storage Technologies' Application Potentials in Renewable Energy Sources Grid Integration," Sustainability, vol. 12, no. 24, Art. no. 24, Jan. 2020, doi: 10.3390/su122410511.

[18] B. V. Mathiesen et al., "Smart Energy Systems for coherent 100\% renewable energy and transport solutions," Appl. Energy, vol. 145, pp. 139-154, May 2015, doi: 10.1016/j.apenergy.2015.01.075.

[19] "Utility-scale batteries and pumped storage return about $80 \%$ of the electricity they store - Today in Energy - U.S. Energy Information Administration (EIA)." https://www.eia.gov/todayinenergy/detail.php?id=46756 (accessed Aug. 02, 2021).

[20] B. Ćosić, G. Krajačić, and N. Duić, "A 100\% renewable energy system in the year 2050: The case of Macedonia," Energy, vol. 48, no. 1, pp. 80-87, Dec. 2012, doi: 10.1016/j.energy.2012.06.078.

[21] S. Zhang and M. Huang, "Microgrid: A strategy to develop distributed renewable energy resource," in 2011 International Conference on Electrical and Control Engineering, Sep. 2011, pp. 3520-3523. doi: 10.1109/ICECENG.2011.6058404. 
[22] M. Alves, R. Segurado, and M. Costa, "Increasing the penetration of renewable energy sources in isolated islands through the interconnection of their power systems. The case of Pico and Faial islands, Azores," Energy, vol. 182, pp. 502-510, Sep. 2019, doi: 10.1016/j.energy.2019.06.081.

[23] H. Lund, A. N. Andersen, P. A. Østergaard, B. V. Mathiesen, and D. Connolly, "From electricity smart grids to smart energy systems - A market operation based approach and understanding," Energy, vol. 42, no. 1, pp. 96-102, Jun. 2012, doi: 10.1016/j.energy.2012.04.003.

[24] Z. Dekali, L. Baghli, and A. Boumediene, "Indirect power control for a Grid Connected Double Fed Induction Generator Based Wind Turbine Emulator," in 2019 International Conference on Advanced Electrical Engineering (ICAEE), Nov. 2019, pp. 1-6. doi: 10.1109/ICAEE47123.2019.9014778.

[25] D. Zouheyr, B. Lotfi, and B. Abdelmadjid, "Improved hardware implementation of a TSR based MPPT algorithm for a low cost connected wind turbine emulator under unbalanced wind speeds," Energy, vol. 232, p. 121039, Oct. 2021, doi: 10.1016/j.energy.2021.121039.

[26] D. Zouheyr, B. Lotfi, L. Thierry, and B. Abdelmadjid, "Grid Side Inverter Control for a Grid Connected Synchronous Generator Based Wind Turbine Experimental Emulator," Eur. J. Electr. Eng., vol. 23, no. 1, pp. 1-7, Feb. 2021, doi: 10.18280/ejee.230101.

[27] M. Merah, L. Baghli, and A. Boumediene, "Prototyping of photovoltaic grid-tie inverter with active and reactive power injection," in 2019 International Conference on Advanced Electrical Engineering (ICAEE), Nov. 2019, pp. 1-6. doi: 10.1109/ICAEE47123.2019.9014764.

[28] L. Baghli, G. Didier, S. BENDALI, and J. Lévêque, “An Open Source Real-Time Power System Simulator with HIL," Oct. 2010.

\section{APPENDIX A.}

Table A.1. Generators transient characteristics

\begin{tabular}{lllllll}
\hline Generators & $\begin{array}{l}H \\
(\mathrm{pu})\end{array}$ & $\begin{array}{l}D \\
(\mathrm{pu})\end{array}$ & $\begin{array}{l}R \\
(\mathrm{pu})\end{array}$ & $\begin{array}{l}X_{d} \\
(\mathrm{pu})\end{array}$ & $\begin{array}{l}P_{\operatorname{m} \max } \\
(\mathrm{pu})\end{array}$ & $\begin{array}{l}E_{g . \max } \\
(\mathrm{pu})\end{array}$ \\
\hline NORTH & 50.0000 & 0.0600 & 0.0000 & 0.2500 & 2.0000 & 2.0000 \\
SOUTH & 01.0000 & 0.1500 & 0.0000 & 1.5000 & 1.0000 & 1.6000 \\
\hline
\end{tabular}

Where $H$ represents the inertia moment, $D$ is the damping, $R$ is the resistance, $X_{d}$ is the transient reactance, $P_{\operatorname{m} m a x}$ is the maximum mechanical power and $E_{g \text {.max }}$ is the maximum electromotive force (e.m.f) of the generators.

Table A.2. The initial data for LF and TS programs 


\begin{tabular}{llll}
\hline Bus & $P_{g}(\mathrm{pu})$ & $P_{L}(\mathrm{pu})$ & $V_{b}(\mathrm{pu})$ \\
\hline NORTH & 1.2957 & 0.0000 & 1.0600 \\
SOUTH & 0.4000 & 0.2000 & 1.0474 \\
LAKE & 0.0000 & 0.4500 & 1.0000 \\
MAIN & 0.0000 & 0.4000 & 1.0000 \\
ELM & 0.0000 & 0.6000 & 1.0000 \\
\hline Total production & 1.6957 & - & - \\
Total consumption & - & 1.6500 & - \\
Total line losses & 0.0457 & - & - \\
\hline
\end{tabular}

Where $P_{g}$ is the generated power, $P_{L}$ is the consumed power (load) and $V_{b}$ is the bus voltage.

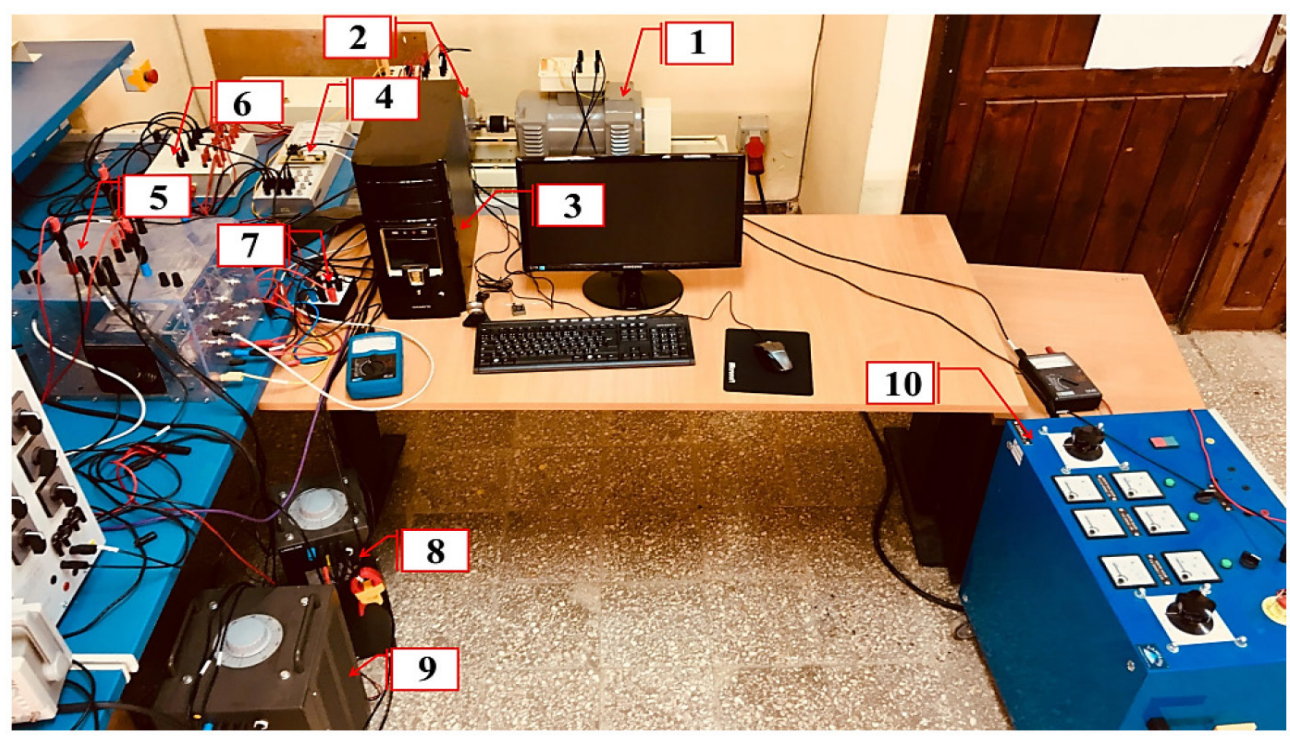

Figure A.1. Experimental hardware setup of the WTE based on a DFIG Table A.3. WTE based on a DFIG hardware components

\begin{tabular}{llll}
\hline Components & Name & Components & Name \\
\hline 1 & DFIG & 6 & Measure interfaces for DFIG \\
2 & DC Motor & 7 & Measure interfaces for DC Motor \\
3 & PC & 8 & Autotransformer (stator side) \\
4 & DS1104 interface & 9 & Autotransformer (rotor side) \\
5 & Inverter and Rectifier & 10 & Power supply (DC excitation) \\
\hline
\end{tabular}




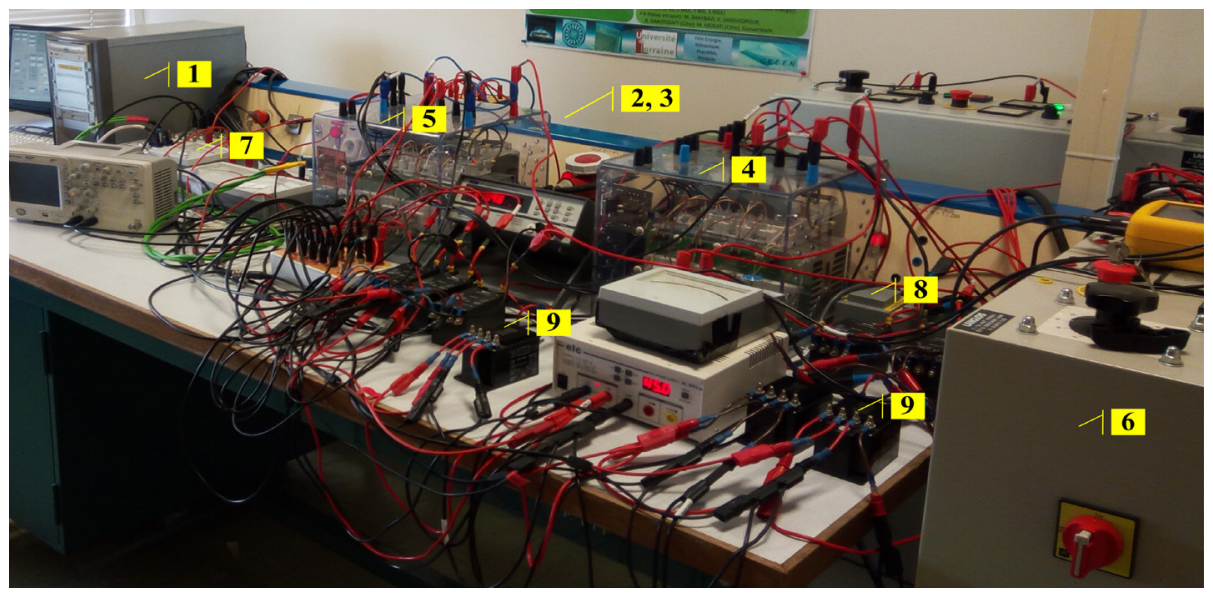

Figure A.2. Experimental hardware setup of the WTE based on a SG

Table A.4. WTE based on a SG hardware components

\begin{tabular}{llll}
\hline Component & Name & Component & Name \\
\hline 1 & PC & 6 & Autotransformer \\
2 & DC Motor & 7 & DS1104 interface \\
3 & SG & 8 & Filter \\
4 & Grid side converter (GSC) & 9 & Sensors \\
5 & Machine side converter (GSC) & & \\
\hline
\end{tabular}

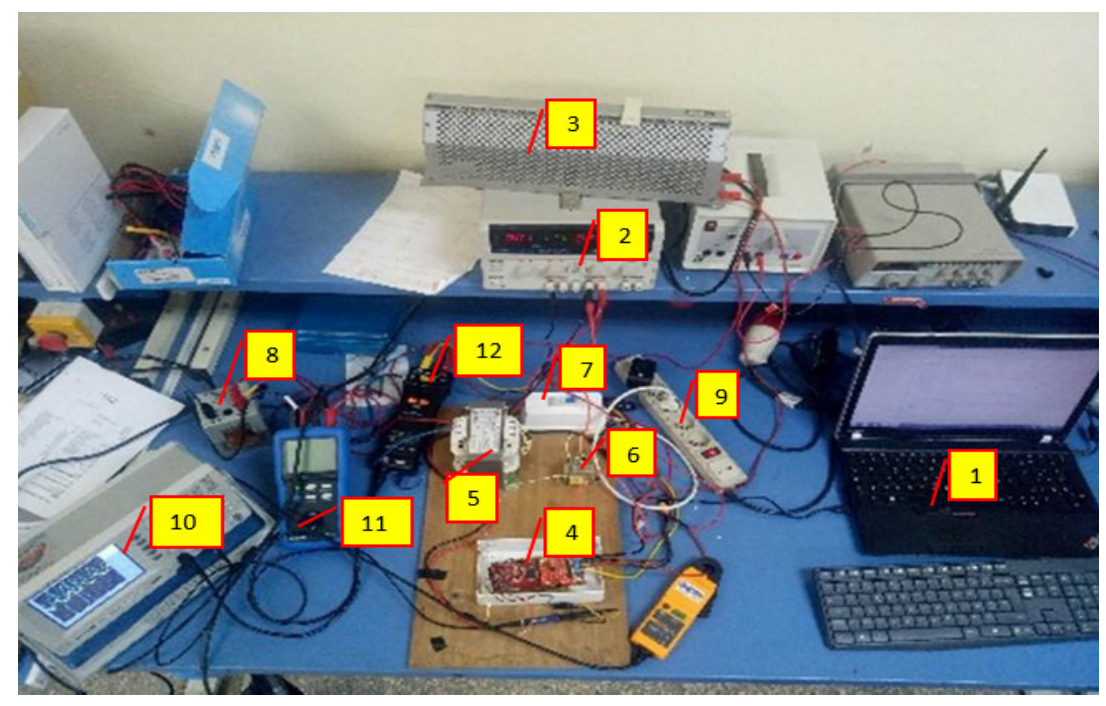

Figure A.3. Experimental hardware setup of the PV self-made MPP

Table A.5. PV self-made MPP hardware components

\begin{tabular}{llll}
\hline Component & Name & Components & Name \\
\hline 1 & PC & 7 & Circuit breaker \\
2 & DC Source & 8 & $5.2 \mathrm{mH}$ Inductance coil \\
3 & Rheostat & 9 & Grid source \\
4 & Measurement boards & 10 & Oscilloscope \\
5 & Transformer 1 (250VA) & 11 & Power meter
\end{tabular}




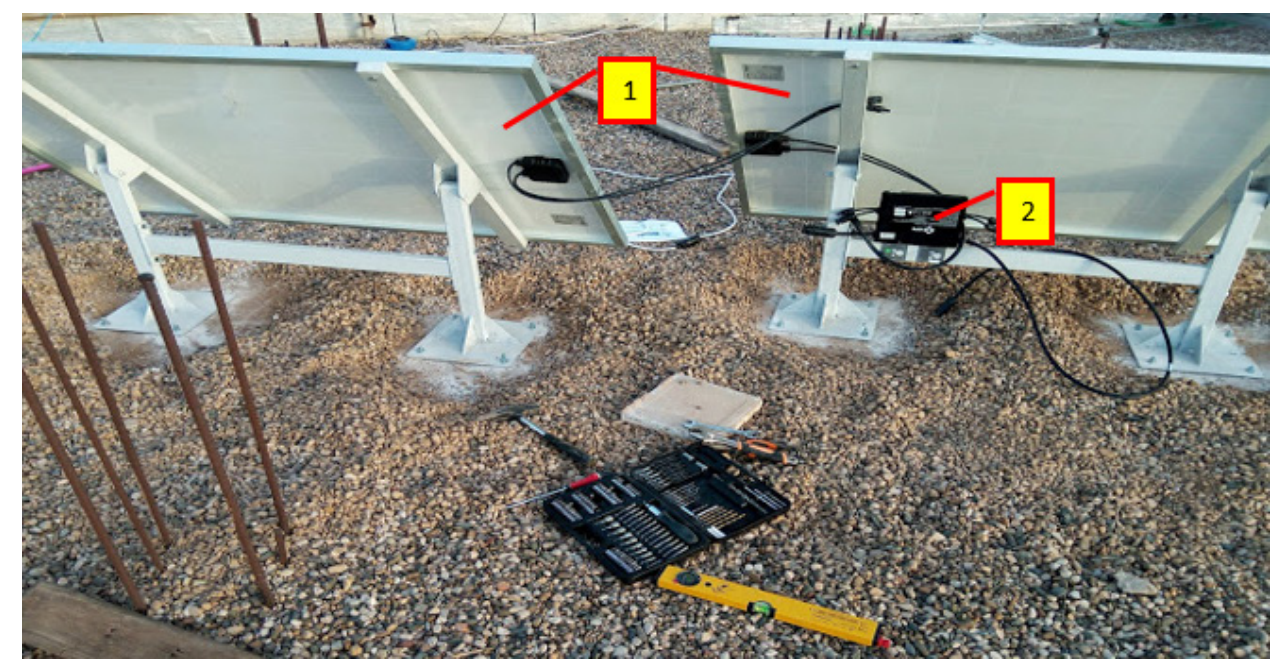

Figure A.4. Experimental hardware setup of the PV industrial MPP

Table A.6. PV industrial MPP hardware components

\begin{tabular}{ll}
\hline Component & Name \\
\hline 1 & Photovoltaic cells (250 W for each one) \\
2 & GTI YC500 \\
\hline
\end{tabular}

